\title{
$A$ and $\mathrm{V}$
}

To the Editorial Committee of the British Journal of OpHThalmology

SIRS,- " "Syndrome is a term applied to a group of symptoms occurring together regularly and thus constituting a disease to which some particular name is given". Thus the definition in Black's Medical Dictionary.

May I make a plea for the abandonment of the phrase " $A$ and $V$ syndromes" in favour of "A and $V$ phenomena".

Yours faithfully,

ROBERT W. STEPHENSON.

4 IMPERIAL SQUare,

Cheltenham,

August 8, 1962.

\section{OBITUARY}

\section{John Pendleton White, M.B., Ch.B.}

Dr. John Pendleton White died suddenly in Glasgow on July 23, 1962, at the age of 67 years. A graduate of Glasgow University, he had a long association with the Glasgow Eye Infirmary, first as House Surgeon and then as Surgeon and University Lecturer for 25 years until his retirement 2 years ago. His early work, however, was centred mainly in Stirling and Falkirk, and the thriving Eye Departments of these Royal Infirmaries are present-day tributes to his pioneering work in the years immediately following the first world war after his service with the R.A.M.C., in Mesopotamia.

A skilful surgeon, he was one of the first in the West of Scotland to adopt the intracapsular method of cataract extraction as a more or less routine procedure; his manipulation of the lens with the intracapsular forceps under rigidly controlled lighting conditions was a joy to observe. His direct and decisive approach was applied also to his clinical work in which he showed a keen sense of balanced judgment. Recently he was President of the Scottish Ophthalmological Club, and in this capacity served on the Council of the Ophthalmological Society of the United Kingdom.

Despite the persistent demands of hospital work and of an extensive consulting practice, Pendleton White always found time to continue his favourite sport of fishing, and also to start, at a relatively late age, to play golf. In typical fashion he tackled this new venture with enthusiasm and determination and soon achieved a considerable degree of skill; a few years ago he was honoured by the Glasgow Golf Club by his election as Captain. Our sympathy is extended to his wife who was devoted to him and to his work for so many years. 